\section{Eosinophilic cholangitis diagnosed endoscopically}

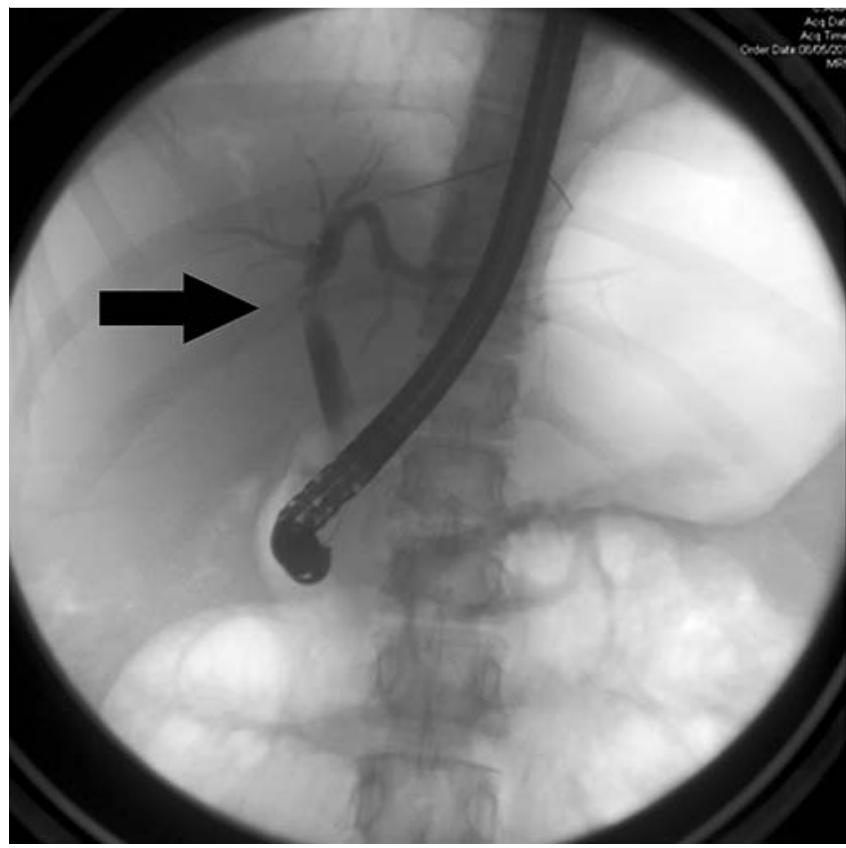

Fig. 1 Radiographic view during endoscopic retrograde cholangiopancreatography (ERCP) in a 15 year old girl with cholestatic jaundice showing a short segment stricture of about $1.5 \mathrm{~cm}$ in the region of the bifurcation (arrow) with proximal dilatation.

A 15 year old girl was referred with cholestatic jaundice, but no other complaints. Biliary obstruction was identified on ultrasound scanning, and abdominal computed tomography (CT) and magnetic resonance cholangiopancreatography (MRCP) demonstrated bilateral dilatation of the intrahepatic bile ducts and an enlarged gallbladder. Endoscopic retrograde cholangiopancreatography (ERCP) revealed a short segment stricture just below the bifurcation ( $\bullet$ Fig. 1). Directed biopsies were taken using the Spyglass cholangioscope and a stent was placed.
Histopathological examination of the biopsies showed an inflammatory infiltrate rich in eosinophils compatible with the diagnosis of eosinophilic cholangitis (๑ Fig. 2).

The patient developed acute cholecystitis 5 days post ERCP and underwent laparoscopic cholecystectomy. Macroscopically, the gallbladder was markedly edematous with intraluminal purulent material. Pathological examination of the gallbladder revealed chronic cholecystitis and focal eosinophilic infiltrates ( Fig.3). The patient was treated with prednisone (initially $60 \mathrm{mg}$, tapered over 6 months) followed by azathioprine (50 mg) as a steroid-sparing agent and underwent repeated endoscopic stent exchanges. A year later she remained asymptomatic with normal liver function tests and a normal ERCP ( $\bullet$ Fig. 4$)$.

We report a case of eosinophilic cholangitis in which the diagnosis was made preoperatively, allowing successful combination therapy with endoscopy and immunosuppression to be implemented.

Eosinophilic cholangitis is an extremely rare benign disease [1], which causes eosinophilic infiltration of the biliary tree and other organs. It can result in the formation of strictures within the biliary tree [2-4], as it is characterized by marked fibrosis of the bile ducts [5]. Eosinophilic cholangitis is part of a spectrum of diseases that all show eosinophilic infiltration of organs, with or without peripheral eosinophilia $[6,7]$. Suggested diagnostic criteria include thickening or obstruction of the bile ducts, infiltration with eosinophils on bile duct biopsy, and improvement with immunosuppression [6].

The present case is one of only a few cases of eosinophilic cholangitis to be diagnosed without surgery, which allowed us to consider other potential therapeutic strategies as alternatives. In addition, our case is the first case, to our knowledge, in which eosinophilic cholangitis was treated with steroids followed by immunosuppressive therapy. Physicians should consider this possibility when treating this eosinophilic condition.

Endoscopy_UCTN_Code_CCL_1AZ_2AN

\section{Competing interests: None}
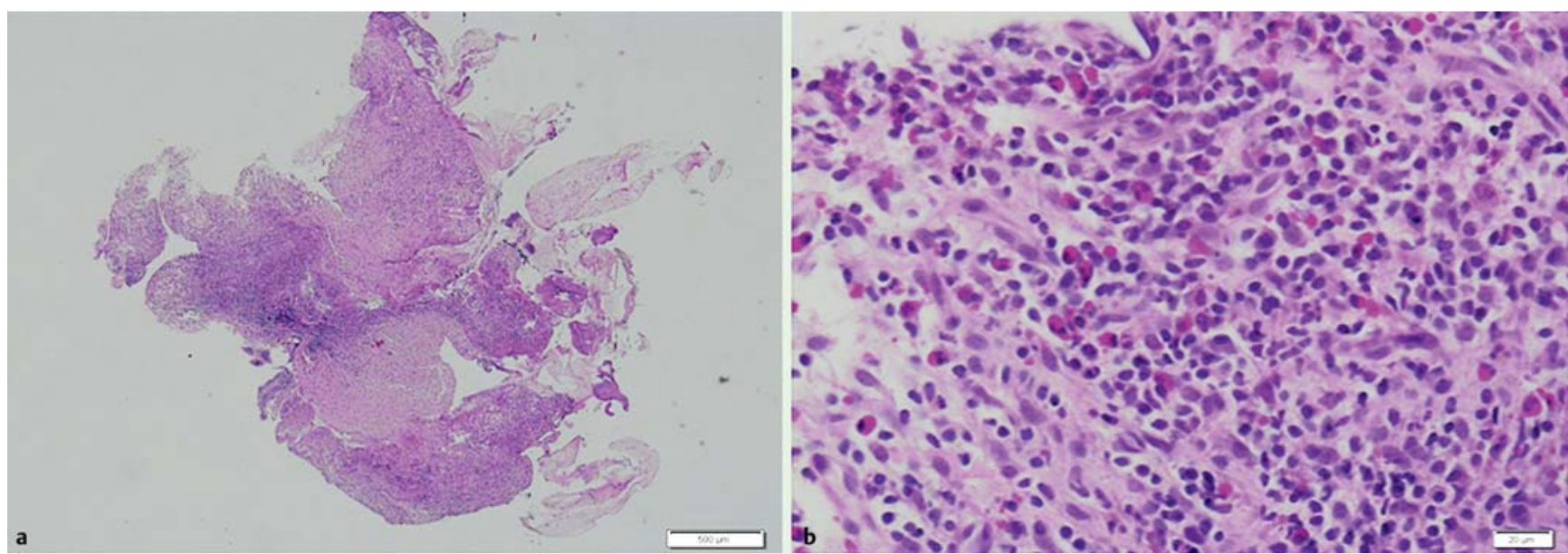

Fig. 2 Histopathology of the biopsy specimens taken by direct visualization using Spyglass cholangioscopy showing: a a fragment of tissue from the common bile duct (magnification $\times 4$ ); $\mathbf{b}$ an inflammatory infiltrate rich in eosinophils compatible with the diagnosis of eosinophilic cholangitis (magnification $\times 40$ ). 

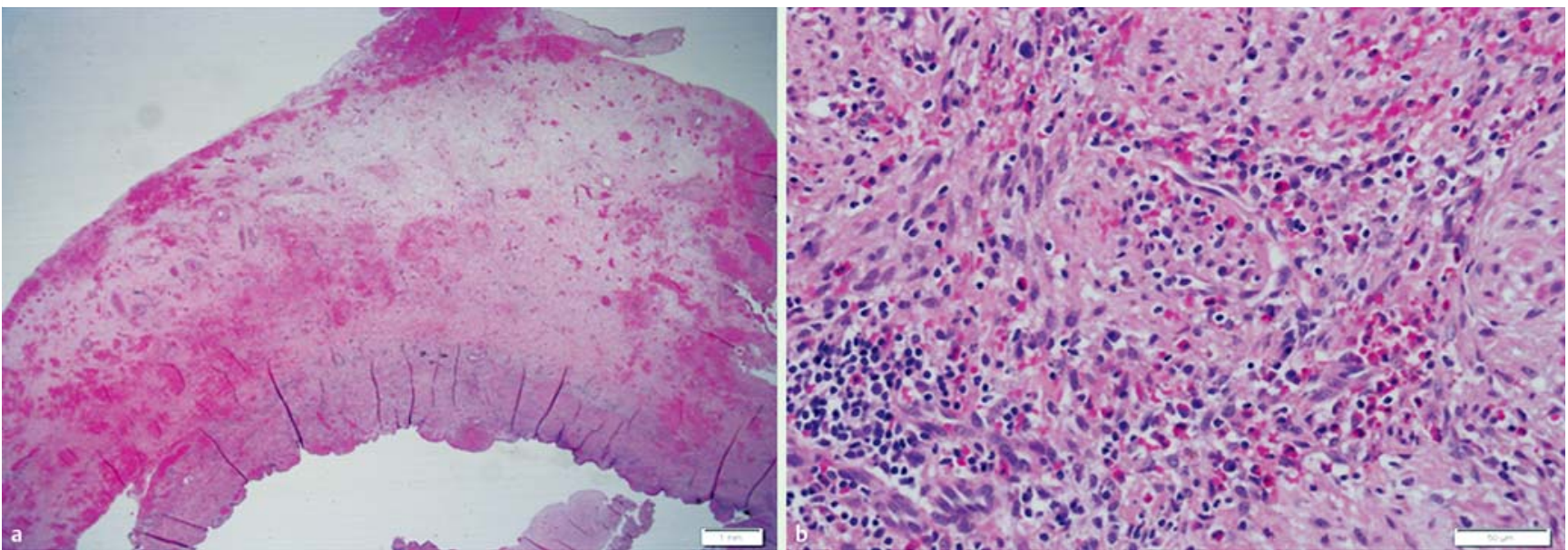

Fig. 3 Histopathology of the resected gallbladder showing chronic cholecystitis with subserosal fibrosis and focal eosinophilic infiltrations (a magnification $\times 4$; b magnification $\times 40$ ).

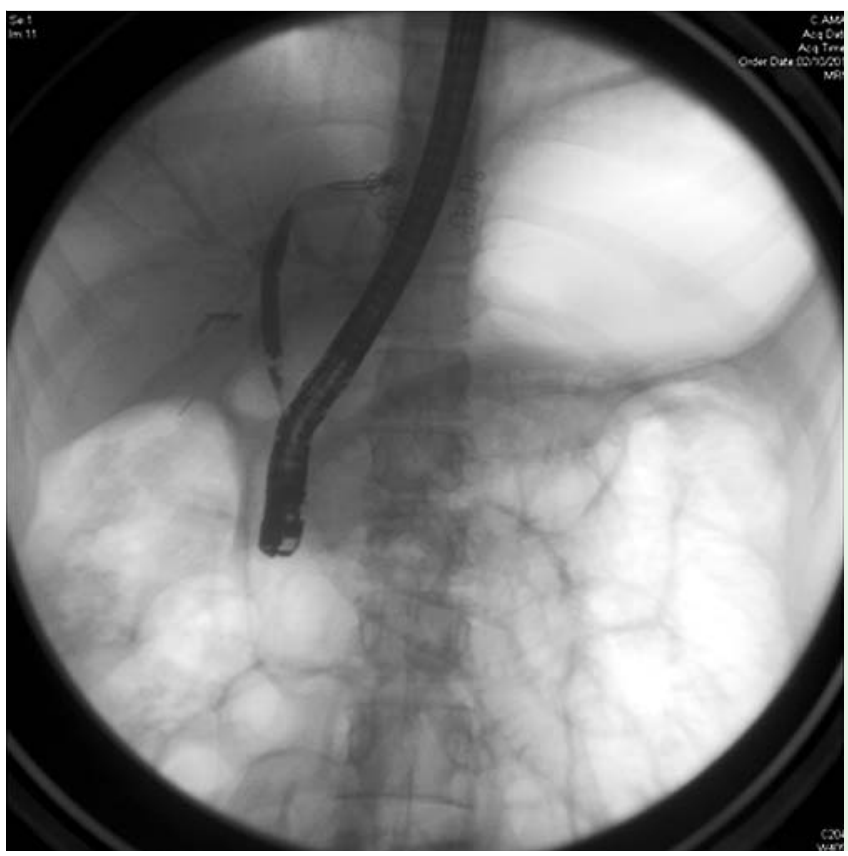

\section{Elez Vainer ${ }^{1}$, Gilad Vainer², Harold Jacob ${ }^{1}$, Mohammad Faroja ${ }^{3}$}

1 Department of Gastroenterology, Hadassa Ein Kerem Hospital, Jerusalem, Israel

${ }^{2}$ Department of Pathology, Souraski Medical Center, Tel Aviv, Israel

${ }^{3}$ Department of Surgery, Hadassah Ein Kerem Medical Center, Jerusalem, Israel
Fig.4 Radiographic view during endoscopic retrograde cholangiopancreatography (ERCP) 1 year later following recurrent endoscopic stent exchanges and immunosuppressive therapy showing a normal common bile duct with no evidence of a stricture.

3 Butler TW, Feintuch TA, Caine WP et al. Eosinophilic cholangitis, lymphadenopathy, and peripheral eosinophilia: a case report. Am J Gastroenterol 1985; 80: 572 - 574

4 Abdalian R, Heathcote EJ. Sclerosing cholangitis: a focus on secondary causes. Hepatology 2006; 44: 1063 - 1074

5 Nashed C, Sakpal SV, Shusharina $V$ et al. Eosinophilic cholangitis and cholangiopathy: a sheep in wolves clothing. HPB Surg 2010; 2010: 906496

6 Matsumoto N, Yokoyama K, Nakai K et al. A case of eosinophilic cholangitis: imaging findings of contrast-enhanced ultrasonography, cholangioscopy, and intraductal ultrasonography. World J Gastroenterol 2007; 13: 1995 - 1997

7 Duseja A, Nada R, Dhiman RK et al. Eosinophilic cholangiopathy - a case report. Dig Dis Sci 2005; 50: $1422-1425$

\section{Bibliography}

DoI http://dx.doi.org/

10.1055/s-0033-1359137

Endoscopy 2014; 46: E95-E96

(c) Georg Thieme Verlag KC

Stuttgart · New York

ISSN 0013-726X

1 Miura F, Asano T, Amano $H$ et al. Resected case of eosinophilic cholangiopathy presenting with secondary sclerosing cholangitis. World J Gastroenterol 2009; 15: 1394 1397

2 Rosengart TK, Rotterdam H, Ranson $\mathrm{JH}$. Eosinophilic cholangitis: a self-limited cause of extrahepatic biliary obstruction. Am J Gastroenterol 1990; 85: 582-585

\section{Corresponding author}

\section{Harold Jacob, MD}

Hadassa Ein Kerem Hospital - Gastroenterology Jerusalem 91120

Israel

Fax: +972-5-02057914

midi18@gmail.com 